\title{
Nuclear Localization Signal of HIV-1 as a Novel Target for Therapeutic Intervention
}

\author{
Larisa Dubrovsky, * Peter Ulrich,* Gerard J. Nuovo, ${ }^{\dagger}$ \\ Kirk R. Manogue,* Anthony Cerami,* and Michael Bukrinsky* \\ *The Picower Institute for Medical Research, Manhasset, New York, \\ U.S.A. 'Department of Pathology, State University of New York, \\ Stony Brook, New York, U.S.A.
}

\begin{abstract}
Background: Human immunodeficiency virus type 1 (HIV-l) is a lentivirus and shares with other members of this retroviral subfamily the ability to replicate in nondividing cells, in particular, cells of the monocyte/ macrophage lineage. This feature relies on the presence of a specific nuclear localization signal (NLS) within the viral matrix protein (MA pl7), which to some degree can be complemented by the activity of the viral vpr gene product. The MA pl7 NLS ensures efficient transportation of the viral preintegration complex into the nucleus of an infected macrophage and confers persistence of HIV-1 in quiescent T cells, and therefore presents an attractive target for therapeutic intervention.

Materials and Methods: Nuclear localization signals (NLS) in general and the HIV-1 MA pl7 NLS in particular are characterized by a stretch of positively charged amino acids including one or more lysine residues. A series of compounds potentially capable of binding and reacting with lysine by forming Schiff base adducts was synthesized. Our special consideration was to make compounds that would preferentially bind to two closely contiguous amino functions, as opposed to isolated single lysine residues. We assumed that this approach might specifically target the compound to NLS while affecting other regions less, thus reducing nonspecific cytotoxicity. Antiviral activity was assessed in primary monocytes and in peripheral blood lymphocytes (PBL) infected with HIV-1 ${ }_{\text {ADA }}$ strain. Viral replication was monitored by reverse transcriptase (RT) activity in the supernatant. Efficiency of nuclear importation of the viral preintegration complex was estimated by the formation of 2-LTR circle
\end{abstract}

forms of HIV-1 DNA and also by in situ PCR techniques.

Results: Arylene bis(methyl ketone) compounds with a nitrogenous third substituent, especially a pyrimidinic side-chain, inhibited HIV-1 replication in human monocytes at an $\mathrm{IC}_{50}$ as low as $1 \mathrm{nM}$. These compounds did not block HIV-1 replication in peripheral blood lymphocyte cultures. The inhibitory effect observed in monocyte cultures appeared in the context of markedly reduced nuclear importation of viral DNA in the presence of the drug. No cytotoxic effects of the compounds was observed in vitro at concentrations as high as $10 \mu \mathrm{M}$. An amidinohydrazone derivative of the most active compound was about 100 times less active than the parent, indicating that carbonyl groups were instrumental in the antiviral effect.

Conclusions: These early results suggest that retroviral replication in nondividing cells is susceptible to pharmaceutical intervention targeted against the NLS activity of HIV-1 proteins in the viral preintegration complex. The compounds described efficiently block translocation of viral DNA to the nuclei of infected primary monocytes, and inhibit viral replication. This inhibition is effective only in nondividing cells and is not seen in proliferating cultures, such as activated PBLs. Thus, drugs that target HIV-1 NLS may be useful to specifically block the macrophage arm of HIV infection and could thereby be of value in treating macrophage-specific manifestations of HIV disease, such as HIV-1 dementia. In combination with other drugs, potential therapeutics exploiting this target may also help to control the progression of HIV-1 infection and disease.

Address correspondence and reprint requests to: Michael Bukrinsky, The Picower Institute for Medical Research, 350 Community Drive, Manhasset, NY 11030, U.S.A. 


\section{INTRODUCTION}

Cells of the monocyte/macrophage lineage are believed to play an extremely important role in the pathogenesis of human immunodeficiency virus (HIV) disease and may also be important in the transmission and progression of infection. Because HIV type 1 (HIV-1) strains isolated from infected individuals during the early stages of infection are predominantly monocytotropic, non-syncytium-inducing viruses (1-4), it appears that monocytes could be the earliest target of HIV infection after introduction into a new host. Low cytopathicity of the virus towards monocytes in vitro suggests that these cells might represent a productive reservoir of HIV in the body, at least early in the course of infection (5-8). Since macrophages are antigen-presenting cells that also regulate immune responses by producing a wide variety of cytokines and other bioactive molecules, HIV infection of this population could in principle account for a significant degree of dysregulation of the immune system (reviewed in Ref. 9 and 10). HIV-infected macrophages are responsible, at least in part, for such devastating and frequent complications of acquired immunodeficiency syndrome (AIDS) as central nervous system (CNS) disease $(6,11-13)$ and pulmonary disease (14-16). Finally, some investigators studying HIV-l-infected chimpanzees have attributed the asymptomatic course of infection in these animals to the lack of a robust macrophage component to the infection (17).

Recent studies have identified nuclear importation of the retroviral preintegration complex as a crucial step in HIV-1 replication in nondividing cells such as monocytes (18). In contrast to HIV-1 replication in proliferating $\mathrm{T}$ cells, where frank disruption of nuclear membrane during mitosis directly exposes cellular genomic DNA to viral preintegration complexes, viral propagation in nondividing monocytes relies on the active energy-dependent translocation of the preintegration complex through the intact nuclear membrane and into the nucleus $(18-20)$. Further work has demonstrated that nuclear importation of the HIV-1 DNA occurs in the context of the high molecular weight complex comprising viral RNA, DNA, and several viral proteins, including matrix antigen (MA p17) and virus protein $\mathrm{R}$ (Vpr) $(21,22)$. This complex can gain access to the host genome of both proliferating and growth-arrested cells $(18,21-23)$. Subsequent analysis revealed that nuclear translocation of the HIV-1 preintegration complex in growth-arrested $\mathrm{T}$ cells and in cultured monocytes relies on the nuclear targeting properties of the MA p17 and Vpr proteins, and in particular on the presence of a nuclear localization signal (NLS) in the $\mathrm{N}$-terminal portion of MA pl7 (22,23).

The HIV-1 MA pl7 NLS belongs to a wellcharacterized class of relatively simple nuclear localization sequences. Generally, nuclear localization signals of this type are distinguished by short stretches of amino acids that contain a high percentage of basic residues. One putative consensus signal that has been proposed is Lys-Lys/ Arg-X-Lys/Arg, where $X$ is one of a variety of amino acids (24). The MA p17 NLS (Gly-Lys-LysLys-Tyr-Lys-Leu-Lys [23]) conforms very well to this consensus sequence. Mutations introduced into MA p17 NLS (e.g., Gly-Thr-Thr-Lys-TyrLys-Leu-Lys) significantly attenuate viral replication in monocytes (22) and viral persistence in quiescent $\mathrm{T}$ cells (25). In addition, nuclear importation of the HIV-1 preintegration complex can be partially inhibited by an excess of the prototypic NLS of simian virus 40 large $T$ antigen (26). These results prompted us to design a series of compounds potentially capable of binding to and reacting with the MA pl7 NLS. In the present article, we describe the rationale behind the synthesis of such compounds and demonstrate their efficacy in blocking HIV-1 replication in primary human monocyte cultures.

\section{MATERIALS AND METHODS}

\section{Synthesis of Compounds}

Compound H-0294 was prepared by reacting 3,5-diacetylaniline (27) with 2-amino-4-chloro6-methylpyrimidine in water with catalytic $\mathrm{HCl}$ at $90-100^{\circ} \mathrm{C}$ for $30 \mathrm{~min}$ followed by base neutralization to give 2-amino-4-(3,5-diacetylphenyl)amino-6-methylpyrimidine, which was methylated by heating at reflux with a 16-fold excess of $1.75 \mathrm{M}$ methyl iodide in 1:1:2 dichloromethane-acetonitrile-tetrahydrofuran for 48 hr. After an aqueous workup, 2-amino-4-(3,5diacetylphenyl)amino - 1,6 - dimethylpyrimidinium iodide (Compound $\mathrm{H}-0294$ ) was isolated as a dihydrate.

Compound $\mathrm{H}-2194$ was prepared by reacting Compound $\mathrm{H}-0294$ with 2.5 equivalents of $0.3 \mathrm{M}$ aminoguanidine hydrochloride in 1:1 methanol: 2-methoxyethanol at reflux for $16 \mathrm{hr}$. 


\section{Cell Cultures and Infection with HIV-1}

Primary human monocytes were obtained from peripheral blood by Ficoll-Hypaque centrifugation and adherence to plastic as described previously (7). Briefly, after Ficoll-Hypaque (Pharmacia) separation, peripheral blood mononuclear cells (PBMCs) were washed four times with Dulbecco's modified Eagle medium (DMEM) (the last wash was done at $800 \mathrm{rpm}$ to remove platelets) and resuspended in monocyte culture medium (DMEM supplemented with $1 \mathrm{mM}$ glutamine, $10 \%$ heat-inactivated human serum, $1 \%$ penicillin+streptomycin mixture [Sigma Chemical Co., St. Louis, Mo., U.S.A.]) at a density of $6 \times 10^{6}$ cells $/ \mathrm{ml}$. Cells were seeded in 24-well plates ( $1 \mathrm{ml}$ per well) and incubated for $2 \mathrm{hr}$ at $37^{\circ} \mathrm{C}, 5 \% \mathrm{CO}_{2}$. Following incubation, cells were washed three times with DMEM to remove nonadherent cells and incubation was continued in monocyte culture medium supplemented with $250 \mathrm{U} / \mathrm{ml}$ human M-CSF (Sigma). Cells were allowed to mature for 7 days prior to infection with the monocyte-tropic strain, HIV$1_{\mathrm{ADA}}(28)$. Two hours after infection, cells were washed with medium and cultured in RPMI supplemented with $10 \%$ human serum. In experiments where polymerase chain reaction (PCR) analysis was performed, virus was pretreated with RNAse-free DNAse (Boehinger-Mannheim) for $2 \mathrm{hr}$ at room temperature and then filtered through a $0.2-\mu \mathrm{m}$ pore nitrocellulose membrane prior to infection.

PBMCs were purified by Ficoll-Hypaque centrifugation and activated by $10 \mu \mathrm{g} / \mathrm{ml}$ phytohemagglutin (PHA)-P (Sigma) and $20 \mathrm{U} / \mathrm{ml}$ recombinant human IL-2 (rhIL-2) in RPMI 1640 supplemented with $10 \%$ fetal bovine serum (FBS) (HyClone). After $24 \mathrm{hr}$ incubation, cells were washed and inoculated with $\mathrm{HIV}-1_{\mathrm{ADA}}$ in RPMI 1640 supplemented with 10\% FBS. After a $2 \mathrm{hr}$ adsorption, free virus was washed away and cells were cultured in RPMI 1640 supplemented with $10 \%$ PBS and $20 \mathrm{U} / \mathrm{ml}$ rhIL-2.

\section{p24 and RT Assay}

For the p24 assay, sequential 1:9 dilutions of culture supernatant were prepared and analyzed by ELISA as suggested by the manufacturer (Cellular Products, Buffalo, NY, U.S.A.). For the reverse transcriptase (RT) assay, $10 \mu \mathrm{l}$ of culture supernatant was added to $40 \mu \mathrm{l}$ of reaction mixture (final composition was $50 \mathrm{mM}$ Tris- $\mathrm{HCl}$, $\mathrm{pH}$ 7.8; $20 \mathrm{mM} \mathrm{KCl} ; 5 \mathrm{mM} \mathrm{MgCl} 2 ; 1 \mathrm{mM} \mathrm{DTT} ; 0.1 \%$
Triton X-100; $0.2 \mathrm{OD} / \mathrm{ml}$ polyA; $0.2 \mathrm{OD} / \mathrm{ml}$ oligo(dT) ${ }_{12-18} ;$ and $40 \mu \mathrm{Ci} / \mathrm{ml}{ }^{3} \mathrm{H}-\mathrm{dTTP}(76 \mathrm{Ci} /$ mmol, DuPont) and incubated $2 \mathrm{hr}$ at $37^{\circ} \mathrm{C} .5 \mu \mathrm{l}$ of the reaction mixture was then spotted onto the DE 81 (Whatman) paper. The paper was air dried and washed five times with $5 \% \mathrm{Na}_{2} \mathrm{HPO}_{4}$, followed by rinsing with distilled water. After air drying, the paper was put on a Flexi Filter plate (Packard), covered with scintillation fluid, and counted in a Top Count Microplate Counter (Packard). Results are expressed as counts per minute in $1 \mathrm{ml}$ of supernatant $(\mathrm{cpm} / \mathrm{ml})$.

\section{Assay of the HIV-1 Nuclear Translocation}

Efficiency of nuclear translocation was estimated by the ratio between the 2-LTR-and pol-specific PCR products, which reflects the portion of 2-LTR circle DNA molecules as a fraction of the entire pool of intracellular HIV-1 DNA. Viral 2-LTR circle DNA is formed exclusively within the nucleus of infected cells and thus is a convenient marker of successful nuclear translocation $(18,23)$.

PCR ANALYSIS OF HIV-1 DNA. Total DNA was extracted from HIV-1-infected cells using the IsoQuick extraction kit (Microprobe Corp., Garden Grove, CA, U.S.A.). DNA was then analyzed by PCR using primer pairs that amplify the following sequences $(18,21,29)$ : a fragment of HIV-l (LTR/gag) that is the last one to be synthesized during reverse transcription and therefore represents the pool of full-length viral DNA molecules; a fragment of polymerase gene (pol); a 2-LTR junction region found only in HIV-1 2-LTR circle DNA molecules; or a fragment of the cellular $\alpha$-tubulin gene. Dilutions of 8E5 cells (containing one integrated copy of HIV-1 DNA per genome) into CEM cells were used as standards. Amplification products were transferred to nylon membrane filters and hybridized to ${ }^{32} \mathrm{P}$-labeled oligonucleotides corresponding to internal sequences specific for each PCR amplification fragment $(18,29)$, followed by exposure to Kodak XAR-5 film or a phosphor screen.

QUANTITATION OF PCR REACTIONS. Bands of correct size revealed after hybridization were quantitated with a PhosphorImager (Molecular Dynamics) by measuring the total density (integrated volume) of rectangles enclosing the corresponding product band. Efficiency of nuclear translocation of HIV-1 DNA was estimated by measurement of the amount of 2-LTR circle 
DNA $\left(N_{\text {2-LTR }}\right)$ relative to total viral DNA $\left(N_{\text {tot }}\right)$ in each culture, indexed to the same ratio of appropriate control cultures

$$
\frac{\mathrm{C}_{2-\mathrm{LTR}}}{\mathrm{C}_{\text {tot }}} .
$$

The nuclear translocation index was then defined as

$$
\left(\frac{\frac{N_{\text {2-LTR }}}{N_{\text {tot }}}}{\frac{C_{\text {2-LTR }}}{C_{\text {tot }}}}\right) \times 100 \% .
$$

\section{PCR in Situ Hybridization}

Detection of PCR-amplified HIV-1 DNA in fixed tissue culture samples was accomplished using a previously published protocol (30-33). Briefly, after protease digestion (with $2 \mathrm{mg} / \mathrm{ml}$ pepsin at room temperature for $30 \mathrm{~min}$ ), PCR was performed using a solution which contained PCR buffer (GeneAmp kit, Perkin Elmer Corporation, Norwalk, Conn., U.S.A.), $4.5 \mathrm{mM} \mathrm{MgCl}_{2}, 200$ $\mu \mathrm{M}$ dNTPs, $1.0 \mu \mathrm{M}$ of the primers (SK38/SK39 or SK145/SK431 [30]), $1 \mathrm{mg} / \mathrm{ml}$ of bovine serum albumin and 2.5 Units $/ 25 \mu$ l of Taq DNA polymerase. The "hot start modification", whereby Taq DNA polymerase is added to the amplifying solution at $55^{\circ} \mathrm{C}$ increases the sensitivity of the assay to one copy with a single primer pair (32). After an initial denaturation step of $94^{\circ} \mathrm{C}$ for 3 min, 30 cycles were completed using the following protocol: annealing/extension at $55^{\circ} \mathrm{C}$ for 2 min, denaturation at $94^{\circ} \mathrm{C}$ for $1 \mathrm{~min}$. After PCR, the probe (SK19 for SK38/39 and SK102 for SK145/431 [30]) at $50 \mathrm{ng} / \mathrm{ml}$ in a solution of $10 \%$ formamide, $5 \%$ dextran sulfate, and 300 $\mathrm{mM} \mathrm{NaCl}$, and amplified DNA are simultaneously denatured by heating to $100^{\circ} \mathrm{C}$ for 5 $\mathrm{min}$. After the hybridization $\left(2 \mathrm{hr}\right.$ at $\left.37^{\circ} \mathrm{C}\right)$ and wash steps ( $10 \mathrm{~min}$ in $1 \times \mathrm{SSC}$ and $0.2 \%$ bovine serum albumin at $50^{\circ} \mathrm{C}$ ) the slides are incubated in anti-digoxigenin-alkaline phosphatase conjugate (1:100 dilution, Boehinger Mannheim, Indianapolis, Ind., U.S.A.) at $37^{\circ} \mathrm{C}$ for $30 \mathrm{~min}$, and the probe/target complex detected by incubation with chomagen, NBT/BCIP (ONCOR Corporation, Gaithersburg, Md., U.S.A.). A hybridization signal is evident as a dark blue precipitate, whereas the counterstain, Nuclear Fast Red, stains nuclei and cytoplasm pale pink. Negative controls were done with a separate cytospin on the same slide and included either mock-ampli-

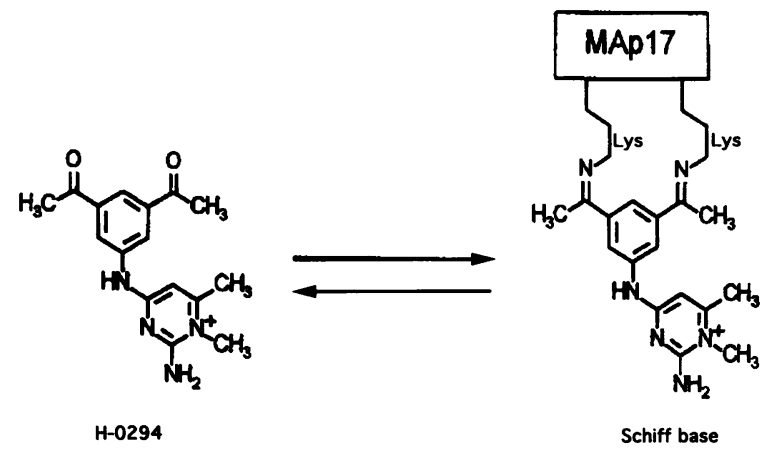

FIG. 1. Presumed interaction of anti-NLS compounds with HIV-1 MA p17 NLS

One of the anti-NLS compounds, H-0294, is shown. Reversible reaction of a carbonyl group with an amino group of any lysine (including those within the MA pl7 NLS) results in the formation of a Schiff base. Formation of two Schiff bases after reaction with the adjacent lysines characteristic of nuclear localization signals would stabilize the bimolecular complex, shifting the equilibrium toward product formation.

fication in the absence of the Taq polymerase or amplification with primers specific for human papilloma virus (31) in place of the HIV-1 specific primers; each control consistently gave negative results.

\section{RESULTS}

\section{Arylene Bis(methyl ketone) Compounds Block HIV-1 Replication in Primary Human Monocytes}

Nuclear localization signals (NLS) are generally characterized by a stretch of basic amino acids, comprised mostly of lysine residues (reviewed in Ref. 34). We reasoned that by designing divalent carbonyl-containing compounds that potentially could interact with closely adjacent amino groups to form Schiff bases (Fig. 1), we could preferentially target the typical lysine-rich NLS sequences, while avoiding highly stable binding to other protein segments. Schiff base formation is a reversible chemical reaction, and we surmised that creation of a double Schiff-base structure with two nearby lysine residues in the NLS would result in a more stable adduct than a single Schiff base formed on an isolated lysine or other amino group (Fig. 1). Also, $\varepsilon$-amino groups of lysine residues within the context of the other 


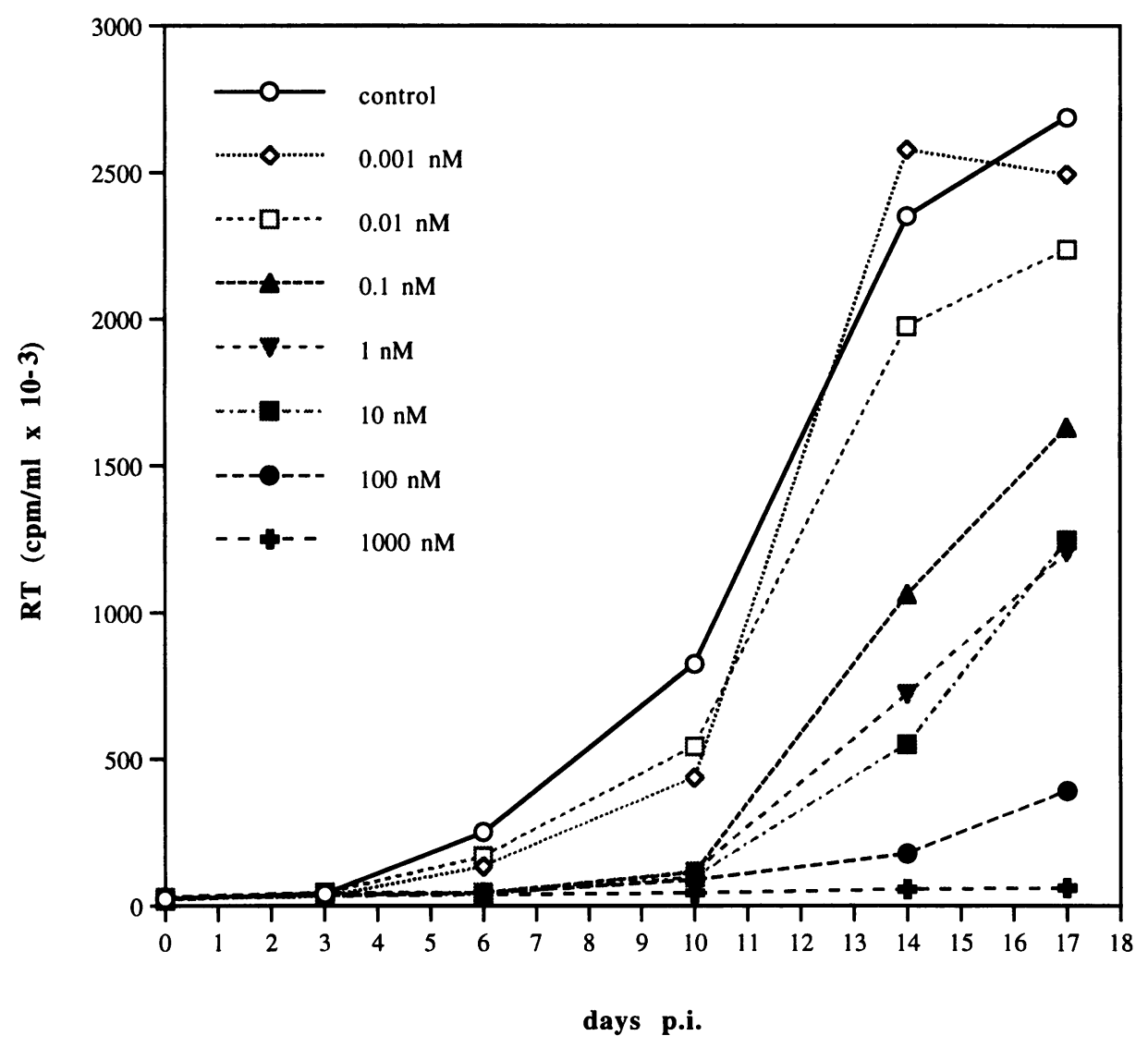

FIG. 2. Dose response curves of H-0294 in human monocytes infected with HIV-1 $\mathbf{A D A}_{\text {AD }}$

Monocyte cultures were infected with HIV-1 $1_{\mathrm{ADA}}$ with MOI $1 \mathrm{ng}$ p24/10 ${ }^{6}$ cells in the presence of indicated concentrations of H-0294. After an overnight incubation, free virus was washed away, medium was changed, and incubation was continued in the presence of drug. Half the volume of culture medium was changed every 3-4 days, and samples were withdrawn for RT analysis at the same time. A representative experiment out of three performed with cells from different donors is shown. Each concentration of the drug was assayed in triplicate and presented data are means.

basic amino acids comprising the NLS should have a higher probability of being neutral rather than positively charged (due to reciprocal repulsion of positive charges), and might therefore be more susceptible to reaction with carbonyls to produce Schiff base adducts. With these considerations, we synthesized a series of mono- and divalent ketoaryl compounds with different modifications in the side groups (P. Ulrich, L. Dubrovsky, A. Cerami, and M. Bukrinsky, manuscript in preparation). Several of these compounds demonstrated pronounced anti-HIV effects in primary human monocyte cultures. In this report, we describe the inhibitory effect of one of the compounds, H-0294, on HIV-1 replication in monocytes and provide an initial functional characterization of this inhibition.

\section{Compound H-0294 Inhibits HIV-1 Replication in Primary Monocytes with $\mathrm{IC}_{50} \approx 1 \mathrm{nM}$}

The potential cytotoxicity of $\mathrm{H}-0294$ was tested in monocyte cultures by trypan blue exclusion assay or lactate dehydrogenase (LDH) release. By either assay, no cytotoxic eifect was observed at concentrations of the compound up to $10 \mu \mathrm{M}$ (data not shown).

Results presented in Fig. 2 show the effect of various concentrations of H-0294 on HIV-1 replication in monocytes. From this experiment, we estimated that the $\mathrm{IC}_{50}$ for this compound fell between 1 and $10 \mathrm{nM}$. At $1 \mu \mathrm{M}, \mathrm{H}-0294$ inhibited HIV-1 replication in monocytes by more than $95 \%$. In the presence of inhibitory concentrations of $\mathrm{H}-0294$, we observed not only a delay 
A.

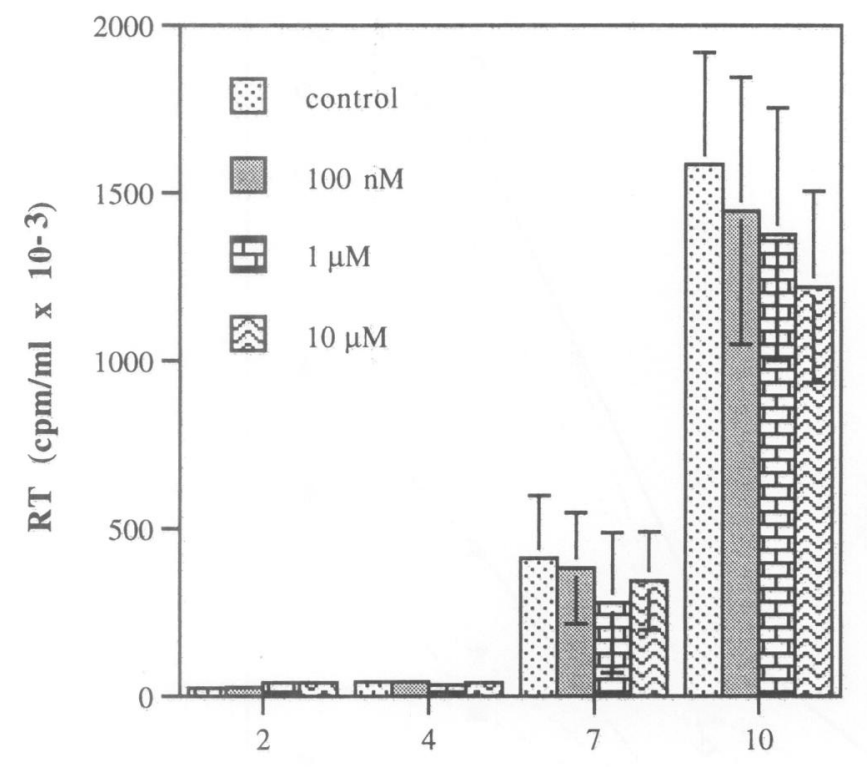

days after infection
B.

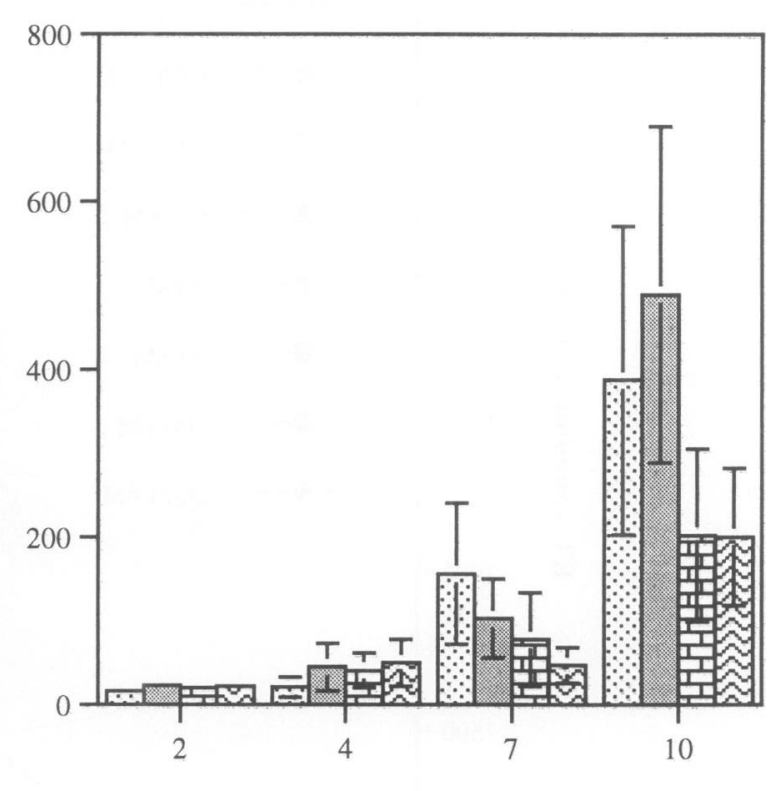

days after infection

FIG. 3. Effect of H-0294 on HIV-1 replication in activated PBLs

RT activity in culture supernatants was assessed at the indicated days postinfection as described in Materials and Methods. Cultures were infected and maintained under concentrations of H-0294 as indicated (key indicating con-

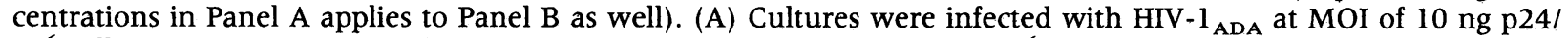
$10^{6}$ cells. (B) Cultures were infected with HIV-1 ${ }_{\mathrm{ADA}}$ at MOI of $1 \mathrm{ng} \mathrm{p} 24 / 10^{6}$ cells. Note difference in $y$-axis scales between Panels A and B.

in the development of infection but also a decrease in total RT activity at the peak of infection, thus indicating an irreversible inactivation of the virus by the compound. The compound was also tested on activated PBL cultures and, in accordance with our prediction, the antiviral effect was much less evident in these actively dividing cell populations (Fig. 3). In fact, no antiviral effect was detected if cultures of replicating PBLs were infected at the multiplicity of $10 \mathrm{ng} \mathrm{p} 24 / 10^{6}$ cells (Fig. 3A), the same MOI as used to infect monocyte cultures, although some inhibition was observed when dividing PBL cultures were infected at a 10-fold lower MOI (Fig. 3B).

Since we hypothesized that the activity of $\mathrm{H}-0294$ depended on its two carbonyl groups, we tested a derivative of this drug that had amidinohydrazone groups substituting both carbonyls (Compound H-2194). In agreement with our prediction, $\mathrm{H}-2194$ was significantly less active than H-0294 in monocyte cultures (Fig. 4). The estimated $\mathrm{IC}_{50}$ for $\mathrm{H}-2.194$ is about 100 times higher (approximately $100 \mathrm{nM}$ ) than for the
H-0294. Plausible explanations for the residual antiviral activity of $\mathrm{H}-2194$ are the presence of small amounts of the unreacted parent compound (H-0294), and/or the hydrolysis of $\mathrm{H}-2194$ guanylhydrazones to reconstitute active carbonyl groups.

\section{Compound H-0294 Blocks Nuclear Importation of HIV-1 DNA}

The effect of H-0294 appeared to reproduce the effect of NLS mutations $(22,23)$. To further substantiate this possible molecular mechanism of action, we analyzed the effect of this arylene bis(methyl ketone) compound on synthesis and nuclear importation of the viral genome following infection of monocytes. Results presented in Fig. 5 A, B demonstrate that the drug did not significantly affect viral reverse transcription in infected cultures but dramatically reduced the fraction of total HIV-1 DNA represented by 2-LTR circle forms. Quantitative evaluation by 
<smiles>CC(=O)c1cc(Nc2cc(C)[n+](C)c(N)n2)cc(C(C)=O)c1</smiles>

H-0294<smiles>C/C(=N\NC(=N)N)c1cc(Nc2cc(C)[n+](C)c(N)n2)cc(/C(C)=N/NC(=N)N)c1</smiles>

H-2194

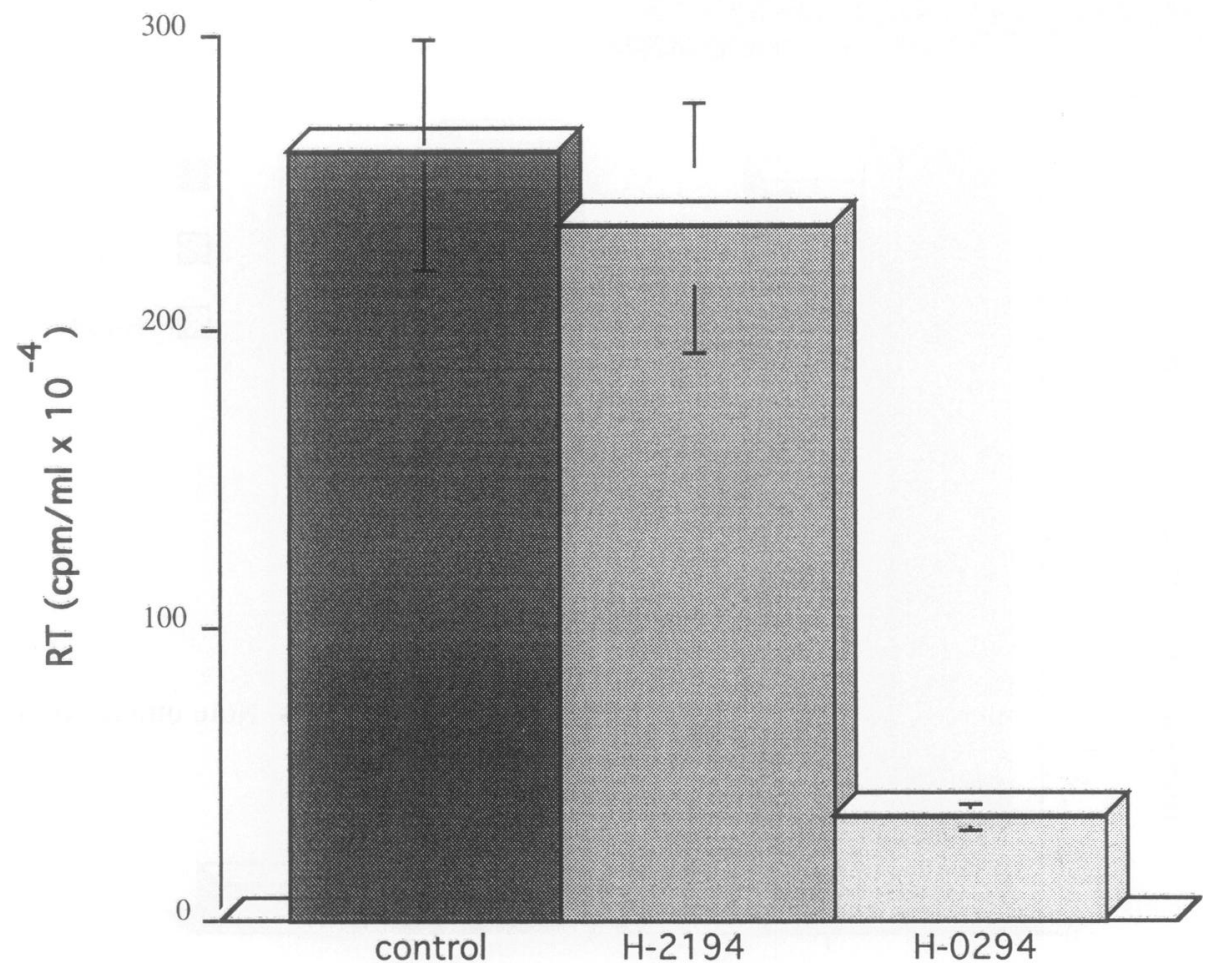

FIG. 4. Inhibition of HIV-1 nuclear translocation by H-0294 relies on the presence of carbonyl groups Primary human monocytes were infected with $\mathrm{HIV}-\mathrm{I}_{\mathrm{ADA}}$ in the presence of $10 \mathrm{nM}$ concentration of $\mathrm{H}-0294$ or H-2 194, or without drugs (control). Half the medium was changed every 3 days, and drugs were present throughout the whole experiment. Results of the RT analysis done on the 10th day after infection are presented. Each sample was assayed in quadriplicate and data are means $\pm \mathrm{SD}$.

Phosphorimager analysis showed 2-LTR circle DNA to be $95 \%$ lower at $48 \mathrm{hr}$ and $97 \%$ lower at $96 \mathrm{hr}$ after infection in treated cultures (Fig. 5B). Interestingly, similar analysis for H-2194 demonstrated only $5-8 \%$ reduction in 2-LTR circles, corroborating the difference in potency noted for these compounds in the antiviral test (Fig. 4).

2-LTR circle DNA represents a useful marker for successful nuclear translocation of HIV-l DNA. This index was introduced several years ago (18) and has been shown since then to correlate well with the actual amount of viral DNA within the nuclear compartment $(18,20,22,23$,
26). In addition, we sought an alternative direct demonstration that the potential mechanism of antiviral action of $\mathrm{H}-0294$ is its interference with nuclear translocation of the viral genome. This was accomplished by exploiting an in situ PCR technique (30-32). Results presented in Fig. 6A demonstrated that HIV-1 DNA-specific signal (blue color) remained localized in the cytoplasm of monocytes infected in the presence of $100 \mathrm{nM}$ of H-0294. Control infections show normal nuclear localization of the HIV-1 DNA-specific signal (Fig. 6B). Control amplifications performed without Taq polymerase or with HIV-unrelated 


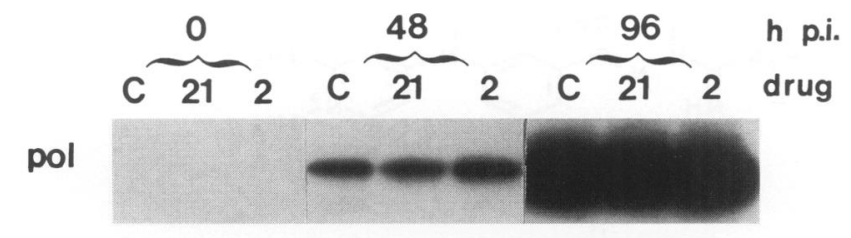
HIV-1 copies
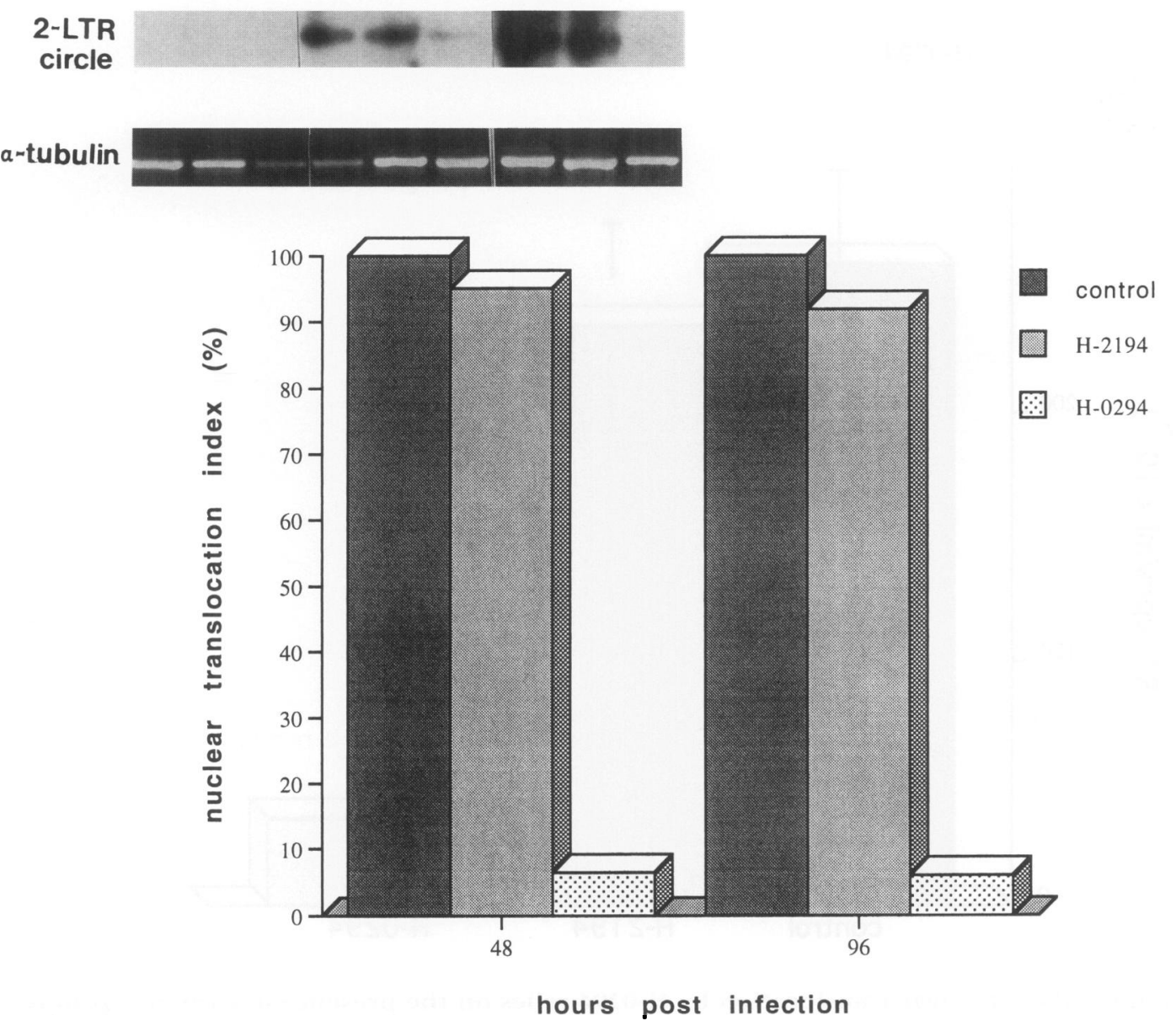

FIG. 5. PCR-based analysis of nuclear translocation of HIV-1 genome

(A) Results of the PCR analysis with primers specific for HIV-1 polymerase gene ( $p o l$ ) and 2-LTR circle junction (2-LTR circle) or for the cellular $\alpha$-tubulin gene. A million monocytes were infected with HIV-1 ${ }_{\text {ADA }}$ in the presence of H-0294 (2) or H-2194 (21). Total cellular DNA was extracted immediately after a 2-hr adsorption period (0 hr p.i.), $48 \mathrm{hr}$ p.i. and $96 \mathrm{hr}$ p.i. HIV-l-specific products were revealed after Southern hybridization to ${ }^{32} \mathrm{P}-\mathrm{la}-$ beled probe, while the tubulin-specific fragment was revealed by staining the gel with ethidium-bromide. Control infection (C) was performed without drugs. Results of the PCR reactions with serial dilutions of 8E5 cells, each containing one integrated copy of HIV-1 genome (53), using pol-specific primers are shown on the right. The number of HIV-1 copies in each dilution is shown above the corresponding lane. (B) Results of the experiment described in Fig. 4A were analyzed on a phosphorimager. Nuclear translocation index is expressed as

$$
\left(\frac{\frac{\mathrm{N}_{2-\mathrm{LTR}}}{\mathrm{N}_{\text {tot }}}}{\frac{\mathrm{C}_{2-\mathrm{LTR}}}{\mathrm{C}_{\text {tot }}}}\right) \times 100 \%
$$




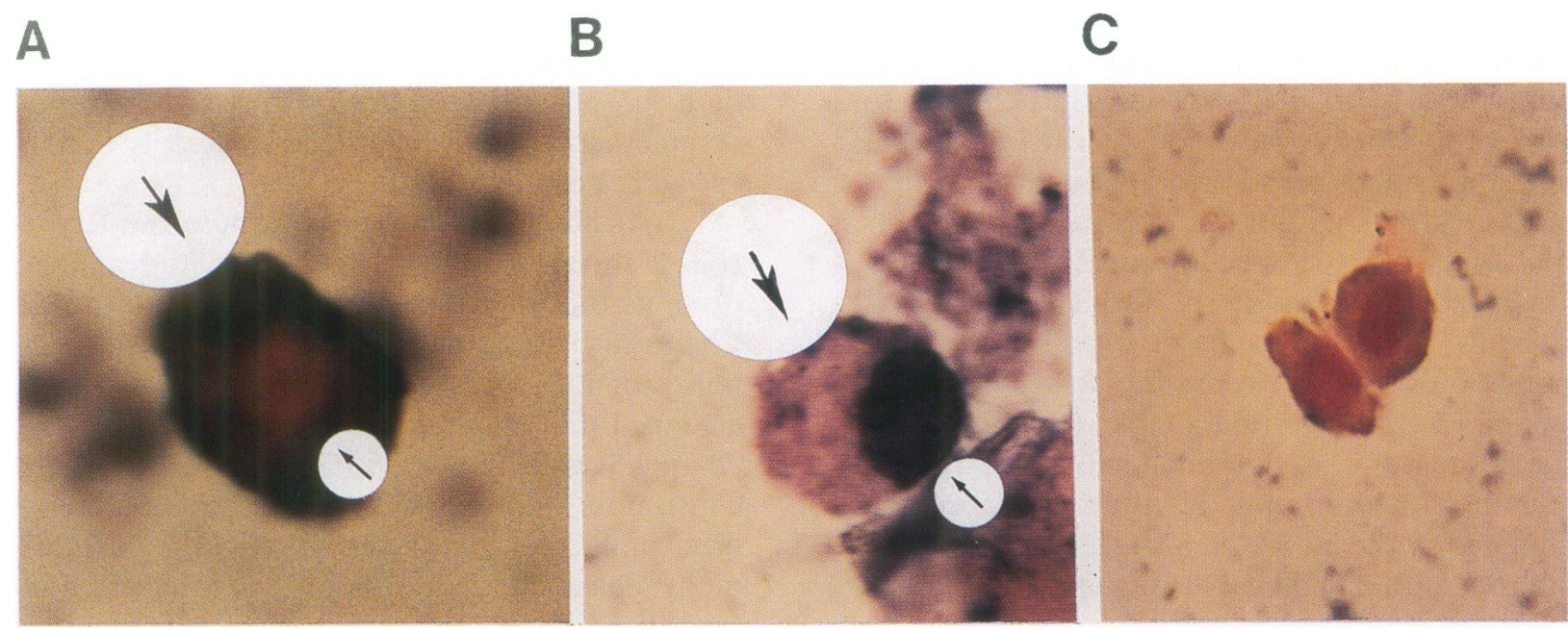

FIG. 6. PCR in situ hybridization analysis of HIV-1-infected monocytes

Monocytes were inoculated with $10 \mathrm{ng} \mathrm{p} 24 / 10^{6}$ cells of HIV-1 $\mathrm{ADA}$, washed after $2 \mathrm{hr}$ absorption and incubated for additional $48 \mathrm{hr}$. One hundred nanomolar concentration of H-0294 was present in experimental samples at all steps of the procedure. At the end of a 48-hr incubation, culture medium was removed, cells were washed three times with PBS and fixed with $10 \%$ buffered formalin for $24 \mathrm{hr}$. Monocytes were scraped from the plate with rubber policemen and analyzed by in situ PCR as described in Materials and Methods. (A) Monocytes treated with $\mathrm{H}-0294$; (B) untreated (control) infected monocytes; (C) negative control (without Taq polymerase). Large arrows point to the cytoplasm, and small arrows to nuclei.

primers do not show HIV-specific DNA staining (Fig. 6C).

\section{DISCUSSION}

Since the discovery of HIV as the causative and pathogenic agent of AIDS, a number of potentially useful strategies for antiviral therapy have emerged (reviewed in Ref. 35 and 36). These strategies have targeted various steps of HIV replication, from binding of the virus to its cellular receptor as the initial step of infection, to the assembly of mature HIV virions and their budding from the cell membrane during the final steps. Unfortunately, relatively few drug candidates developed as a result of these endeavors have emerged as useful and efficient therapeutics in clinical practice (reviewed in Ref. 37). The rapid evolution of escape mutants owing to the extreme genetic lability of the virus, combined with the very nature of the retroviral life cycle, where the infectious agent integrates into the host cell genome and replicates in the same manner as normal cellular genes, have prominently mitigated against successful drug discovery efforts. Given the difficulty of interfering with expression of the virus once provirus has become established in the cellular genome, pharmaceu- tical approaches that target early, preintegration steps of HIV replication remain attractive strategies.

One of the early obligate steps in retroviral replication within an infected cell is the translocation of the viral genetic material into the cell nucleus (19). This requirement was previously unappreciated as a potential target for antiretroviral therapy because most retroviruses rely on the natural disruption of the nuclear membrane during mitosis to gain access to the nuclear compartment, therefore depending on cell division for productive infection $(20,38)$. HIV-l and other members of the lentivirus subfamily of retroviruses have in addition a different mechanism to achieve nuclear access. This mechanism is employed for HIV-1 replication in nondividing cells $(39,40)$ and depends on the nuclear targeting properties of two viral proteins, MA p17 and Vpr (18-20,22,25). Recent studies have identified a specific nuclear localization signal (NLS) within MA pl7 which is responsible for targeting the preintegration complex of HIV-l into the nucleus of a nondividing cell $(23,25)$. The HIV-1 NLS conforms closely to other well-characterized nuclear localization sequences (34), comprising a stretch of basic amino acids, predominantly lysine residues (23). The NLS-dependent nuclear translocation of the HIV-1 genome represents an 
appealing target for anti-HIV therapy because: (i) it functions prior to viral integration, such that interference with this step has the potential to prevent productive infection of the cell; (ii) it relies on a characteristic well-defined set of molecular features within the NLS that are in principal amenable to specific chemical modifications; (iii) the activity of the HIV-1 NLS is critically sensitive to base substitutions that change only one or two amino acids within the peptide (34), suggesting that a few molecular changes within the NLS can inactivate its nuclear targeting function; and (iv) the well conserved sequence of the HIV-1 NLS suggests that escape mutants still capable of using this mechanism may evolve only infrequently.

Recognizing this potential vulnerability, a set of compounds potentially capable of binding and reacting with the free $\varepsilon$-amino groups of lysine residues was synthesized and tested. Some of the compounds (i.e., H-0294) proved to be extremely potent inhibitors of HIV-1 replication in monocytes, with an $\mathrm{IC}_{50}$ in the low $\mathrm{nM}$ range. For maximal effect, these drugs had to be added to static monocyte cultures during the early stages of infection (within $24 \mathrm{hrs}$ after addition of the virus to cells). This result correlates well with the kinetic of HIV-1 replication in monocytes, which shows accumulation of HIV-1 DNA within the nucleus by 24-48 hr after inoculation (M. Bukrinsky, unpublished results). No effect of the drugs on the expression of integrated provirus by activated U1 (monocytic cell line) or ACH2 (T cell line) cells was observed (data not shown). Likewise, the antiviral effect of the compounds on HIV-1 infection in activated PBL cultures was limited, and revealed only at low multiplicity of infection (MOI). At the standard MOI employed in macrophage screening experiments, no antiviral activity of the compounds was detected in dividing PBL cultures. Taken together, these results support the hypothesis that compounds designed to modify the HIV-1 NLS can be effective antiviral agents in nondividing cells when administered prior to integration of the viral cDNA into the host genome.

Complete inhibition of viral replication by H-0294 was achieved at relatively low MOI, 10 ng p24 per $10^{6}$ cells (about 200 HIV-1 particles per cell [41]) under our experimental conditions. Experimental infection at higher MOI resulted in low but measurable levels of viral production even in the presence of relatively high concentrations $(1 \mu \mathrm{M})$ of the drug. This result may in part be attributable to the small number of divid- ing cells in monocyte cultures (42), which could support low levels of HIV-1 replication independent of MA pl7 NLS function, and to the complementation of MA p17 NLS activity by the vpr gene product (22).

To achieve nuclear translocation, the HIV-1 NLS is thought to be recognized by the cellular proteins that mediate nuclear importation (43). Chemical disruption of these cellular/viral protein/protein interactions may have been achieved by elimination of required positive charges within the NLS and/or through sterical constraints imposed by the presence of bulky drug molecules at the recognition site. Experiments designed to test directly the interaction of potential anti-NLS drugs with molecular features of the HIV-1 nuclear localization signal and to define the nature, stability, and kinetics of this interaction are now in progress. Several lines of evidence already available, however, tend to corroborate the intended direct interaction between anti-NLS compounds and MA p17 as the actual mechanism of action of anti-NLS compounds: (1) H-0294 efficiently blocks nuclear translocation of the HIV-1 genome (Fig. 5 and 6); (2) chemical derivatives of $\mathrm{H}-0294$ lacking active carbonyl groups (e.g., H-2194), the functional groups intended to interact with the retroviral NLS, demonstrate greatly decreased antiviral activity (Fig. 4); and (3) the high specific activity of anti-NLS compounds for HIV-1 replication in nondividing cells versus a markedly lower benefit in actively dividing cultures correlates with the suggested mechanism.

\section{Perspectives for the Use of Anti-NLS Compounds as Anti-HIV Drugs}

Only future animal studies and human clinical trials can directly assess whether anti-NLS compounds can contribute to the pharmaceutical arsenal against HIV disease. It is perhaps encouraging, however, that the intended target populations of this new class of potential therapeutics are nondividing cells. Maturation of macrophages in vivo requires only few, if any, cell divisions (reviewed in Ref. 44), and at which stage in its life cycle the macrophage is infected by HIV-1 remains controversial $(40,42)$. Although under some in vitro conditions, HIV-1 replication in monocytes appears to depend on cell proliferation $(42,45)$, there is convincing evidence that cell division is not absolutely required for HIV-l infection of macrophages (40), 
and certain macrophage populations highly susceptible to HIV-1 infection (e.g., microglial cells) do not divide at all under in vitro culture conditions, as evidenced by ${ }^{3} \mathrm{H}$-thymidine incorporation and BrdU staining (46) (M. Dubois-Dalcq, personal communication). Thus the potential for anti-NLS compounds to block HIV-1 infection in macrophage populations in vivo appears well founded, and at a minimum this class of inhibitors may be useful in establishing the distinct roles of macrophage and microglial infections in the clinical manifestations of HIV disease.

The utility of anti-NLS compounds may also extend, albeit to a lesser degree, to other cell types susceptible to HIV infection. Infection of quiescent $\mathrm{T}$ cells by HIV-1 has been shown to take place in vitro $(47,48)$, and probably constitutes an important pathway for the spread of infection in vivo at various stages of the disease (29). Although HIV-1 does not establish productive replication in quiescent $\mathrm{T}$ cells, the extrachromosomal retroviral DNA can persist in the cytoplasm of such cells for a considerable period of time, and initiate replication upon activation of the host cell $(25,47,49,50)$. A recent report suggests that the duration of viral persistence in the quiescent $\mathrm{T}$ cell depends on the presence of a functional NLS (25), thus widening the potential HIV infection-limiting role of the anti-NLS class of drug candidates. In this regard, it was encouraging that antiviral effects of $\mathrm{H}-0294$ were apparent in activated PBL cultures, even if only at low MOI. This potentially indicates that a functional NLS also enhances viral replication in proliferating cell populations, supporting the use of antiNLS compounds in this context as well.

For maximal effect, anti-NLS drugs should be present at the earliest possible time after exposure of the host to infective virus. During early stages of the infection, macrophages and cells of the macrophage lineage (i.e., dendritic cells) may be the primary reservoir of HIV-1 in the body, supporting infection of $\mathrm{T}$ cells by antigen presentation activities (51) as well as via the release of free virus. Direct cell-to-cell transmission of the virus may constitute the major route by which infection spreads during the early stages of the disease, after resolution of the initial viremia. The molecular mechanisms of this mode of transmission are still obscure, but to the extent that nondividing cells are involved, functional NLS activity to provide access to the host cell genome will also be required and a corresponding therapeutic opportunity may therefore exist despite the absence of free virus in the blood. The realization of this possibility will depend on the design of anti-NLS compounds that are sufficiently membrane permeable to penetrate to intracellular compartments. Our preliminary experiments indicate that $\mathrm{H}-0294$, for instance, can inhibit HIV-I infection in vitro when only the viral inoculum is pre-exposed to drug and the culture remains subsequently untreated (L. Dubrovsky and M. Bukrinsky, unpublished results). Since the HIV envelope is budded from the host membrane, this suggests that anti-NLS drug candidates can be designed to diffuse through the cell membrane.

Although the potential benefits of early initiation of anti-NLS therapy seem the most promising in principle, these compounds may be helpful even if administered later in the disease. It is well established that macrophages, through the abnormal production of cytokines and other biologically active molecules, may mediate significantly the immune dysregulation observed in AIDS (reviewed in Ref. 52). Therefore, reduction in the number of infected macrophages could potentially reduce the disruption of normal immune functions in HIV-infected individuals.

After identifying the HIV-l nuclear localization signal on MA pl7 as a potentially vulnerable retroviral target and experimentally demonstrating its critical function for viral replication in nondividing cells, we were able to design a set of candidate drugs specifically to interfere with this retroviral target. As a class, anti-NLS compounds may be useful not only against HIV, but also against other viruses that replicate in nondividing cells and therefore require nuclear transport for replication, for instance, the measles virus, which replicates in macrophages or the herpes virus that infects neurons. As the development of such anti-NLS compounds progresses, they are likely to be of particular value in combination therapy with other therapeutics that target the $\mathrm{T}$ cell arm of HIV-1 infection to alleviate the progression of HIV disease.

\section{ACKNOWLEDGMENTS}

This work was supported in part by Grant AI 33776 from National Institutes of Health and 02059-15-RGR from AmFAR to MB.

\section{REFERENCES}

1. Connor RI, Mohri H, Cao Y, Ho DD. (1993) Increased viral burden and cytopathicity correlate temporally with CD4+ T-lymphocyte 
decline and clinical progression in human immunodeficiency virus type 1-infected individuals. J. Virol. 67: 1772-1777.

2. Roos MTL, Lange JMA, de Goede REY, et al. (1992) Viral phenotype and immune response in primary human immunodeficiency virus type 1 infection. $J$. Infect. Dis. 165: 427-432.

3. Zhu T, Mo H, Wang N, et al. (1993) Genotypic and phenotypic characterization of HIV-1 patients with primary infection. Science 261: 1179-1181.

4. Schuitemaker H, Koot M, Koostra NA, et al. (1992) Biological phenotype of human immunodeficiency virus type 1 clones at different stages of infection: Progression of disease is associated with a shift from monocytotropic to T-cell-tropic populations. J. Virol. 66: 1354-1360.

5. Gendelman HE, Orenstein JM, Baca LM, et al. (1989) The macrophage in the persistence and pathogenesis of HIV infection [see comments]. AIDS 3: 475-495.

6. Koenig S, Gendelman HE, Orenstein JM, et al. (1986) Detection of AIDS virus in macrophages in brain tissue from AIDS patients with encephalopathy. Science 233: 10891093.

7. Gartner S, Markovits P, Markovits DM, Kaplan MH, Gallo RC, Popovic M. (1986) The role of mononuclear phagocytes in HTLV-III/LAV infection. Science 233: 215219.

8. Popovic M, Gartner S. (1987) Isolation of HIV-l from monocytes but not $\mathrm{T}$ lymphocytes. Lancet 2: 916.

9. Rosenberg Z, Fauci A. (1990) Immunopathogenic mechanisms of HIV infection: Cytokine induction of HIV expression. Immunol. Today 11: 176-180.

10. Rosenberg ZF, Fauci AS. (1993) Immunology of HIV infection. In: Paul WE (ed). Fundamental Immunology. Raven Press, New York, pp. 1375-1397.

11. Navia BA, Jordan BD, Price RW. (1986) The AIDS dementia complex. I. Clinical features. Ann. Neurol. 19: 517-524.

12. Wiley CA, Schrier RD, Nelson JA, Lampert PW, Oldstone MBA. (1986) Cellular localization of human immunodeficiency virus infection within the brains of acquired immune deficiency syndrome patients. Proc. Natl. Acad. Sci. U.S.A. 83: 7089-7093.

13. Wiley CA, Nelson JA. (1990) Human immunodeficiency virus: Infection of the nervous system. Curr. Top. Microbiol. Immunol. 160: 157-172.

14. Salahuddin SZ, Rose RM, Groopman JE, Markham PD, Gallo RC. (1986) Human T lymphotropic virus type III infection of human alveolar macrophages. Blood 68: 281287.

15. Pearce TE, Nowakowski M, Eden E, et al. (1993) Uniform detection of HIV-1 in alveolar macrophages of pediatric but not adult AIDS patients. J. Leukoc. Biol. 53: 722-726.

16. Meltzer MS, Kornbluth RS, Hansen B, Dhawan S, Gendelman HE. (1993) HIV infection of the lung. Role of virus-infected macrophages in the pathophysiology of pulmonary disease. Chest 103: 103S-108S.

17. Schuitemaker H, Meyaard L, Kootstra NA, et al. (1993) Lack of T-cell dysfunction and programmed cell death in human immunodeficiency type- 1 infected chimpanzees correlates with absence of monocytotropic variants. J. Infect. Dis. 168: 1140-1147.

18. Bukrinsky MI, Sharova N, Dempsey MP, et al. (1992) Active nuclear import of human immunodeficiency virus type 1 preintegration complex. Proc. Natl. Acad. Sci. U.S.A. 89: 6580-6584.

19. Stevenson $M$, Bukrinsky $M$, Haggerty $S$. (1992) HIV-1 replication and potential targets for intervention. AIDS Res. Hum. Retrovir. 8: 107-117.

20. Lewis P, Emerman M. (1994) Passage through mitosis is required for oncoretroviruses but not for the human immunodeficiency virus. J. Virol. 68: 510-516.

21. Bukrinsky MI, Sharova N, McDonald TL, Pushkarskaya T, Tarpley WG, Stevenson $M$. (1993) Association of integrase, matrix, and reverse transcriptase antigens of human immunodeficiency virus type 1 with viral nucleic acids following acute infection. Proc. Natl. Acad. Sci. U.S.A. 90: 6125-6129.

22. Heinzinger $N$, Bukrinsky $M$, Haggerty $S$, et al. (1994) The Vpr protein of human immunodeficiency virus type 1 influences nuclear localization of viral nucleic acids in non-dividing host cells. Proc. Natl. Acad. Sci. U.S.A. 91: 7311-7315.

23. Bukrinsky MI, Haggerty S, Dempsey MP, et al. (1993) A nuclear localization signal within HIV-1 matrix protein that governs infection of non-dividing cells. Nature 365: 666-669.

24. Chelsky D, Ralph R, Jonak G. (1989) Sequence requirements for synthetic peptide- 
mediated translocation to the nucleus. Mol. Cell. Biol. 9: 2487-2492.

25. von Schwedler U, Kornbluth RS, Trono D. (1994) The nuclear localization signal of the matrix protein of human immunodeficiency virus type 1 allows the establishment of infection in macrophages and quiescent $\mathrm{T}$ lymphocytes. Proc. Natl. Acad. Sci. U.S.A. 91: 6992-6996.

26. Gulizia J, Dempsey MP, Sharova N, et al. (1994) Reduced nuclear import of human immunodeficiency virus type 1 preintegration complexes in the presence of a prototypic nuclear targeting signal. J. Virol. 68: 2021-2025.

27. Ulrich P, Cerami A. (1984) Trypanocidal 1,3arylene diketone bis(guanylhydrazone)s. Structure-activity relationships among substituted and heterocyclic analogues. J. Med. Chem. 27: 35-40.

28. Gendelman HE, Orenstein JM, Martin MA, et al. (1988) Efficient isolation and propagation of human immunodeficiency virus on recombinant colony-stimulating factor 1-treated monocytes. J. Exp. Med. 167: $1428-1441$.

29. Bukrinsky MI, Stanwick TL, Dempsey MP, Stevenson M. (1991) Quiescent T lymphocytes as an inducible virus reservoir in HIV-1 infection. Science 254: 423-427.

30. Nuovo GJ, Margiotta M, MacConnell P, Becker J. (1992) Rapid in situ detection of PCR-amplified HIV-1 DNA. Diagn. Mol. Pathol. 1: 98-102.

31. Nuovo GJ, Gallery F, MacConnell P, Becker J, Bloch W. (1991) An improved technique for the detection of DNA by in situ hybridization after PCR-amplification. Am. J. Pathol. 139: 1239-1244.

32. Nuovo GJ. (1992) PCR in Situ Hybridization: Protocols and Applications. Raven Press, New York.

33. Nuovo GJ, Gallery F, MacConnell P, Braun A. (1994) In situ detection of polymerase chain reaction-amplified HIV-1 nucleic acids and tumor necrosis factor- $\alpha$ RNA in the central nervous system. Am. J. Pathol. 144: 659666.

34. Richter JD, Standiford D. (1992) Structure and regulation of nuclear localization signals. In: Feldherr CM (ed). Nuclear Trafficking. Academic Press, San Diego, pp. 90-121.

35. Mitsuya H, Yarchoan R, Kageyama S, Broder S. (1991) Targeted therapy of human immu- nodeficiency virus-related disease. F.A.S.E. B. J. 5: 2369-2381.

36. Yarchoan R, Pluda JM, Perno CF, Mitsuya H, Broder S. (1991) Anti-retroviral therapy of HIV infection: Current strategies and challenges for the future. Blood 78: 859-884.

37. Mitsuya H, Yarchoan R. (1994) Development of antiretroviral therapy for AIDS and related disorders. In: Broder S, Merigan TC, Bolognesi D (eds). Textbook of AIDS Medicine. Williams \& Wilkins, Baltimore, pp. 721-742.

38. Roe TY, Reynolds TC, Yu G, Brown PO. (1993) Integration of murine leukemia virus DNA depends on mitosis. E.M.B.O. J. 12: 2099-2108.

39. Li G, Simm M, Potash MJ, Volsky DJ. (1993) Human immunodeficiency virus type I DNA synthesis, integration, and efficient replication in growth-arrested T cells. J. Virol. 67: 3969-3977.

40. Weinberg JB, Matthews TJ, Cullen BR, Malim MH. (1991) Productive human immunodeficiency virus type 1 (HIV-1) infection of nonproliferating human monocytes. J. Exp. Med. 174: 1477-1482.

41. Layne SP, Merges MJ, Dembo $M$, et al. (1992) Factors underlying spontaneous inactivation and susceptibility to neutralization of human immunodeficiency virus. Virology 189: 695-714.

42. Schuitemaker H, Kootstra NA, Koppelman $\mathrm{MH}$, et al. (1992) Proliferation-dependent HIV-1 infection of monocytes occurs during differentiation into macrophages. J. Clin. Invest. 89: 1154-1160.

43. Yamasaki L, Lanford RE. (1992) Nuclear transport receptors: Specificity amid diversity. In: Feldherr CM (ed). Nuclear Trafficking. Academic Press, San Diego, pp. 122-174.

44. van Furth $R$, Diesselhoff-den Dulk MMC, Raeburn JA, Zwet TL, Crofton RW, van Oud Albas AB. (1980) Characteristics, origin and kinetics of human and murine mononuclear phagocytes. In: van Furth R (ed). Mononuclear Phagocytes. Functional Aspects. Martinus Nijhoff, Hague, pp. 279-300.

45. Koyanagi Y, O'Brien WA, Zhao JQ, Golde DW, Gasson JC, Chen IS. (1988) Cytokines alter production of HIV-1 from primary mononuclear phagocytes. Science 241: 16731675.

46. Watkins BA, Dorn $\mathrm{HH}$, Kelly WB, et al. (1990) Specific tropism of HIV-1 for microglial cells in primary human brain cultures. Science 249: 549-553. 
47. Stevenson M, Haggerty S, Lamonica C, Mann AM, Meier C, Wasiak A. (1990) HIV-1 replication is controlled at the level of $\mathrm{T}$ cell activation and proviral integration. E.M.B.O. J. 9: 1551- 1560 .

48. Zack JA, Arrigo SJ, Weitsman SR, Go AS, Haislip A, Chen IS. (1990) HIV-1 entry into quiescent primary lymphocytes: Molecular analysis reveals a labile, latent viral structure. Cell 61: 213-222.

49. Spina CA, Kwoh TJ, Chowers MY, Guatelli JC, Richman DD. (1994) The importance of nef in the induction of human immunodeficiency virus typa 1 replication from primary quiescent CD4 lymphocytes. J. Exp. Med. 179: $115-123$.

50. Miller MD, Warmerdam MT, Gaston I, Greene WC, Feinberg MB. (1994) The hu- man immunodeficiency virus-1 nef gene product: A positive factor for viral infection and replication in primary lymphocytes and macrophages. J. Exp. Med. 179: 101-113.

51. Pantaleo G, Graziosi C, Demarest JF, et al. (1993) HIV infection is active and progressive in lymphoid tissue during the clinically latent stage of disease. Nature 362: 355358.

52. Ho WZ, Cherukuri R, Douglas SD. (1994) The macrophage and HIV-1. Immunol. Ser. 60: 569-587.

53. Folks TM, Powell D, Lightfoote $M$, et al. (1986) Biological and biochemical characterization of a cloned Leu- $3^{-}$cell surviving infection with the acquired immune deficiency syndrome retrovirus. J. Exp. Med. 164: 280290.

Contributed by A. Cerami on November 28, 1994. 